\title{
Analysis on the Influencing Factors of the Players' Psychological States in Basketball Games Based on the Multiple Linear Regression Model
}

\author{
Teng Yang \\ College of Physical Education, Qiongzhou University, Wuzhishan, China \\ y_angteng@126.com
}

Keywords: basketball game; psychological; influencing factors; multiple linear regression model

\begin{abstract}
The psychological state of the basketball players in the game has a direct influence on the players' performance and the result of the game. In order to make sure that each player has a good psychological state, the first thing needed to do is to study the influencing factors of their psychological states. In this study, by using the multiple linear regression model, a model is established through the scores gained respectively by TMD and participating motivation of the players, technical level, the rude performance of the rival, the unfavorable ruling, the continuous unreasonable behavior of the teammates, the coach's scolding, the audience's interference and the maladjustment of place and facilities. The results of this reach show that the rude performance of the rival, the unfavorable ruling and the continuous unreasonable behavior of the teammates are the main influencing factors of a player's psychological state, the participating motivation of the players, the coach's scolding and the audience's interference also influence a player's psychological state in certain degree; the technical level, place and facilities have less effect on the players' psychological states.
\end{abstract}

\section{Introduction}

The whole nation is setting off an upsurge of basketball since Yao Ming, the champion joined the NBA Houston Rockets. People who are dripping with sweat can be seen at basketball courts everywhere. Comparing basketball especially the basketball game with other sports, the shifting rhythm between attack and defence is faster and the body antagonism between the players is stronger. One head-to-head basketball game may attract thousands of viewers gathering, thus the influences caused by the cheers, whistles, and other voices are very deep. During the game, the athlete's psychological state may suffer a fluctuation, and the stability of the players' psychological state is directly related to the outcome of the game. There are many factors influence the university player psychological states. In order to provide scientific bases for the players' daily psychological training, this study analyzes the influencing degrees of different factors by using the multiple linear regression model.

\section{Research method}

A. Research object

73 players from four basketball teams which are from Hainan University, Hainan Normal University, Qiongzhou College and Haikou College of Economics attending Hainan Province the $8^{\text {th }}$ College Basketball Championship are elected as the research object. The oldest player is 27 years old and the youngest one is 18 years old, the average age is $23.6 \pm 3.5$ years old.

B. Consultation and Interview method

Expert consultation: the psychological factors of college basketball players when playing games are preliminarily determined by consulting the college professional psychology experts, college sports sociological theory teachers, and college basketball professional teachers.

Player interview: comprehending the players' self-identified factors which affect the psychological state during the game by interviewing the 73 players respectively in the four teams.

Combining the two methods, the influencing factors are determined, which are the motivation of the players, technical level, the rude performance of the rival, the unfavorable ruling, the continuous unreasonable coordination of the teammates, the coach's scolding, the audience's interference and the maladjustment of place and facilities. 


\section{Research instrument}

The Profile of Mood State (POMS) is adopted for investigating players' psychological states and a form is designed for investigating the influencing factors that may affect players' psychological states. The main contents can be seen in Table 1.

TABLE I. Investigating sheet of he influencing factors for basketball players' psychological states

\begin{tabular}{|l|l|l|l|l|l|}
\hline \multicolumn{1}{|c|}{ influencing factors } & rarely & low & middle & high & higher \\
\hline motivation & & & & & \\
\hline technical level & & & & & \\
\hline rude performance of the rival & & & & & \\
\hline unfavorable ruling & & & & & \\
\hline continuous unreasonable coordination of teammates & & & & & \\
\hline coach's scolding & & & & & \\
\hline audience's interference & & & & & \\
\hline maladjustment of place and facilities & & & & & \\
\hline
\end{tabular}

Only one option of the five options above can be selected each time. The score of each column is as follows: rarely: 0; low: 1 ; middle: 2 ; high: 3 ; higher: 4 . The higher score means that the item can affect the psychological status of the college basketball player more.

D. Data analysis

Using the SPSS17. Software, setting the motivation of the players, technical level, the rude performance of the rival, the unfavorable ruling, the continuous unreasonable coordination of the teammates, the coach's scolding, the audience's interference and the maladjustment of place and facilities as independent variables and setting the TMD as the dependent variable. Then establishing a multiple linear regression model to analyze the influencing degree of each independent variable on the dependent variable.

\section{The modeling process and results}

A. The Establishment of Multiple Linear Regression Model

Setting the TMD as the dependent variable $y$ and setting the scores gained respectively by the participating motivation of the players, technical level, the rude performance of the rival, the unfavorable ruling, the continuous unreasonable behaviour of the eammates, the coach's scolding, the audience's interference and the maladjustment of place and facilities as $\mathrm{x}_{1}, \mathrm{x}_{2}, \mathrm{x}_{3}, \mathrm{x}_{4}, \mathrm{x}_{5}$,

$\mathrm{x}_{6}, \mathrm{x}_{7}, \mathrm{x}_{8}$, then establishing a multiple linear regression model:

$\hat{y}=b_{0}+b_{1} x_{1}+b_{2} x_{2}+\cdots+b_{8} x_{8}$

Setting the mean value and standard deviation of each independent value as $\bar{x}_{i}$ and $\mathrm{s}_{\mathrm{i} \text {. }}$ then standardizing each score of each player.

$$
x_{i}^{*}=\frac{x_{i}-\bar{x}_{i}}{s_{i}}
$$

Putting the $x_{i}^{*}$ into formula (1) to get $\hat{y}_{i}$, thus this individual residual error ei is

$$
e_{i}=y_{i}-\hat{y}_{i}
$$

The residual sum of square is SSE, then

$$
S S E=\sum e_{i}^{2}=\sum\left(y_{i}-\hat{y}_{i}\right)^{2}
$$

When SSE reaches the minimum value, the coefficients $b_{0}, b_{1}, \ldots, b_{8}$ in the regression equation can be estimated.

B. The scores of the independent variables and dependent variable

The scores of the independent variables and dependent variable in this study are shown in Table 2.

TABLE II. The statistics $\bar{x} \pm S$ of scores of the independent variables and dependent variable

\begin{tabular}{|l|l|}
\hline Factors & $\bar{X} \pm \mathrm{S}$ \\
\hline motivation $\mathrm{x} 1$ & $2.32 \pm 0.54$ \\
\hline technical level x2 & $1.09 \pm 0.11$ \\
\hline rude performance of the rival x3 & $3.18 \pm 0.92$ \\
\hline
\end{tabular}




\begin{tabular}{|l|l|}
\hline unfavorable ruling $\mathrm{x} 4$ & $3.06 \pm 0.88$ \\
\hline continuous unreasonable coordination of teammates x5 & $2.87 \pm 0.80$ \\
\hline coach's scolding x6 & $1.85 \pm 0.39$ \\
\hline audience's interference x7 & $2.53 \pm 0.71$ \\
\hline maladjustment of place and facilities x8 & $0.64 \pm 0.08$ \\
\hline TMD (scores of mood state) y & $135.26 \pm 30.53$ \\
\hline
\end{tabular}

C. The result of the multiple linear regression model

By using SPSS17.0 statistical package, the results of the multiple linear regression model are shown in Table 3.

TABLE III. Results of the multiple linear regression model

\begin{tabular}{|c|c|c|c|c|}
\hline variable & $\begin{array}{l}\text { regression } \\
\text { coefficient }\end{array}$ & $\begin{array}{c}\text { t } \\
\text { value }\end{array}$ & $\begin{array}{c}P \\
\text { value }\end{array}$ & $\begin{array}{l}\text { standardized partial } \\
\text { regression coefficient }\end{array}$ \\
\hline intercept & 38.19 & 5.02 & 0.00 & \\
\hline motivation & 5.92 & 3.67 & 0.02 & 6.67 \\
\hline technical level & 1.75 & 1.76 & 0.09 & 2.13 \\
\hline rude performance of the rival & 10.03 & 6.99 & 0.00 & 12.51 \\
\hline unfavorable ruling & 8.14 & 5.25 & 0.00 & 9.46 \\
\hline $\begin{array}{l}\text { continuous unreasonable } \\
\text { coordination of teammates }\end{array}$ & 7.06 & 4.21 & 0.01 & 7.78 \\
\hline coach's scolding & 3.28 & 2.88 & 0.02 & 4.51 \\
\hline audience's interference & 6.44 & 3.97 & 0.01 & 7.33 \\
\hline $\begin{array}{l}\begin{array}{l}\text { maladjustment of } \\
\text { facilities }\end{array} \\
\end{array}$ & 0.84 & 0.92 & 0.21 & 1.45 \\
\hline
\end{tabular}

From table 3, the final multiple linear regression model is:

$\hat{y}=38.19+5.92 x_{1}+1.75 x_{2}+10.03 x_{3}+8.14 x_{4}+7.06 x_{5}+3.28 x_{6}+6.44 x_{7}+0.84 x_{8}$

D. Analysis

1) The impact of the independent variables on the psychological status of college basketball players when playing games

According to the size of standardized partial regression coefficient of each independent variable, it can be found that the the rude performance of the rival, the unfavorable ruling and the continuous unreasonable coordination of the teammates are the main influencing factors of a player's psychological state, the participating motivation of the players: the coach's scolding and the audience's interference also influence a player's psychological state in certain degree; the technical level, place and facilities have little effect on the players' psychological states.

2) Measures of eliminating the interference psychological status factors of the basketball players

According to the results above, in the basketball match, the following ways will help a lot in reducing the influencing factors to the players' psychological states: strictly abiding by the rules of the match, promoting civilized playing, avoiding the rough foul playing, improving the ruling level, strengthening cooperation and trust among the teammates, enhancing the audience management and appealing civilized watching, guiding the players to put a right attitude towards games, reducing coach's scolding to the players. So that every player will play with their normal level and present a wonderful game to the audience.

\section{Conclusion}

Through this research we can find that it is feasible to use the multiple linear regression models to study the influencing factors of basketball players' psychological states. The results are reliable and scientific. These factors such as motivation of the players, technical level, the rude performance of the rival, the unfavorable ruling, the continuous unreasonable coordination of the teammates, the coach's scolding, the audience's interference will affect the players' psychological states. In the daily training coaches should use different ways to regular players' attitude to matches, strengthen cooperation and trust among players and adopt a friendly communication method instead of scolding. Basketball management units shall also strengthen the management of the club, execute the game system strictly, strengthen the team construction, improve the quality of the referee to reducing the wrong ruling in basketball matches and ensure the justice of the match. 


\section{References}

[1] Liwei Zhang, Weiduo Zhang. Research and Development on Sport Psychology [M]. Beijing : Higher Education Press, 2000 .

[2] Yi Zhang The Analysis on the Main Influencing Factors of the Basketball Players' mood in matches [J]. Hubei Sports Science, 2000, 1.

[3] Huanmei Zhang. Solutions on Basketball game players' adverse psychological states,[J]. Yanan College of Education, 2005,1 ( 19 ) .

[4] 4.Ming XU. A Concise Course on Sports Statistics. [ M ] . Beijing : Beijing Sports University Press ,2004:76 -116.

[5] Chengchao Xie. The Reasons and Adjustment of Under-performance of the Players in Basketball Matches[J]. Sports Adult Education, 2004, ( 20 ).

[6] Xiaofen Wang Sports Statistics and SPSS [M ] : IP , Beijing : People's Sports Publishing, 2002. 2

[7] Yan Wang. Study on Sport Psychology. Beijing: Beijing Sports University Press ,2007: 92248.

[8] Kecheng Sun. Diagnosis on Players' Mood in Sports Competitions[J]. North China Water Conservancy and Hydropower College Journal in Zhengzhou, Henan Province , 2006, 2. 